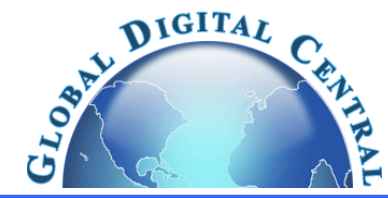

Frontiers in Heat Pipes

Available at www.ThermalFluidsCentral.org

\title{
THE EFFECT OF THICKNESS AND PERMEABILITY OF WICK STRUCTURE ON L-SHAPE HEAT PIPE PERFORMANCE USING DIFFERENT WORKING FLUIDS
}

\author{
Mohamed H. A. Elnaggar \\ Engineering Department, Palestine Technical College, Deir EL-Balah, Gaza Strip, Palestine.
}

\begin{abstract}
This paper presents a two-dimensional FEM simulation of working fluid behavior inside L-shape heat pipe to predict wall temperature and liquid pressure under natural and forced convection modes by using ANSYS-FLOTRAN. This work aimed to numerically study the effect of thickness and permeability of wick structure using different working fluids on L-shape heat pipe performance, where water and methanol were used as working fluids. The heat inputs for natural and forced convection modes comprised $20 \mathrm{~W}$ and $35 \mathrm{~W}$ respectively whereas the heat pipe wick thicknesses were taken as $0.5 \mathrm{~mm}$ and $0.75 \mathrm{~mm}$. The results showed that at forced convection the use of water as working fluid with $0.5 \mathrm{~mm}$ sintered copper wick recorded the smallest temperature difference $\left(9.8^{\circ} \mathrm{C}\right)$ while methanol with $0.75 \mathrm{~mm}$ screen mesh wick recorded the largest temperature difference $\left(28.27^{\circ} \mathrm{C}\right)$.

Keywords: L-shape heat pipe; ANSYS-FLOTRAN; Wick structure; Working fluid; Liquid pressure drop.
\end{abstract}

\section{INTRODUCTION}

Effective cooling of electronic components is important for the successful functioning and high reliability of electronic devices. The rapid developments in microprocessors necessitate enhanced processing power to ensure faster operations. According to (Shao and Zhang 2011), "Local hot spot heat fluxes within the CPU are exceeding $100 \mathrm{~W} / \mathrm{cm}^{2}$ causing the CPU temperature rise, malfunction and failure of CPU without a very effective heat transfer device." Consequently, the requirement for cooling techniques to dissipate the associated heat is of utmost importance. Moreover, the present standard metallic heat sinks are obsolete in many ways and are not sufficient to address the increased cooling needs that are sought by many of today's electronic devices. Hence, it is highly desirable to explore high-performance cooling devices, especially for CPU cooling. Heat pipe has been identified and proved as one of the viable and promising options to achieved this purpose, due to its simple structure, flexibility and in particular, high efficiency.

Substantial numerical and experimental works have been reported on the application of heat pipes for electronic cooling. Reviews by (Faghri 1994), (Groll et al. 1998) and (Vasiliev 2005) provided detailed information on this topic. In addition, the main theoretical and numerical studies on heat pipes with capillary grooved structures were investigated by (Khrustalev and Faghri 1995a; b), (Faghri and Khrustalev 1997), (Khrustalev and Faghri 1999), (Zhang and Faghri 2001), (Jacolot et al. 2008), (Do et al. 2008), (Do and Jang 2010).

Two dimensional models that analyze the liquid and vapor flow and wall temperature along horizontal cylindrical heat pipe are developed by (Mistry et al. 2010), (Nouri-Borujerdi and Layeghi 2004), (Mahjoub and Mahtabroshan 2008). As well, some researchers investigated the flat heat pipes experimentally and numerically such as (Wang and Vafai 2000), (Maziuk et al. 2001), (Carbajal et al. 2007).

The differences in the shape of heat pipe affect its performance as the behaviors of the fluid and the wick structure inside the heat pipe play important role in the transmission of heat. However, the previous works on numerical characterization by taking into account the behavior of the working fluid considered only conventional horizontal cylindrical heat pipe.

In the present study, a two-dimensional FEM simulation of working fluid behavior inside L-shape heat pipe was performed to predict liquid pressure and the wall temperature. The complexity of the simulation of the present heat pipe lies in the fact that the evaporator is at $\mathrm{x}$ direction while the condenser is at $\mathrm{y}$ direction. The simulations were done by using ANSYS-FLOTRAN software and were validated by experimental results. The main objective of this work is to numerically study the effect of thickness and permeability of wick structure using different working fluids on L-shape heat pipe performance as water and methanol were used as working fluids.

\section{MATHEMATICAL FORMULATION}

The finned flat heat pipe under investigation is shown in Fig. 1. This finned heat pipe serves to cool the CPU of a modern notebook such as ASPIRE4720Z with Intel Pentium dual-core processor T2390, $1.86 \mathrm{GHz}$ and memory up to 4 GB DDR2. In this system, the heat pipe is used to transfer heat from CPU to the fins in a remote location, usually in the sides or corners of the notebook PC. The finned flat heat pipe consists of copper base plate of size $30 \mathrm{~mm} \times 30 \mathrm{~mm}$ and condenser section of $72 \mathrm{~mm}$ long, with 50 aluminum rectangular fins of $20 \mathrm{~mm} \times 10 \mathrm{~mm}$ size. The system is supported by radial fan with dimensions of $73 \mathrm{~mm} \times$ $73 \mathrm{~mm} \times 10 \mathrm{~mm}$ (width $\times$ length $\times$ thickness). The specifications of the heat pipe are shown in Fig. 1 and summarized in Table 1.

In this study, the adapted mathematical model was based on the following assumptions: vapor and liquid flows are assumed to be in steady state, laminar and incompressible; the vapor is treated as ideal gas; there is no heat generation due to phase change and chemical reaction in the system; the liquid and vapor phases are coupled at the liquid-vapor interface, and the vapor injection and suction at the liquid vapor interface are uniform; the physical properties are constant. 

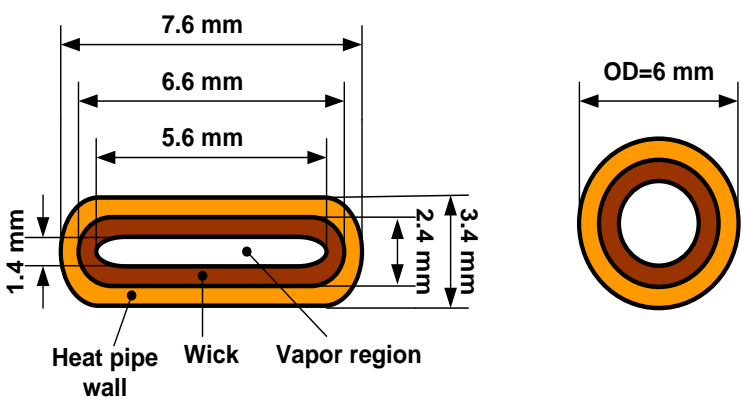

(a) Cross-section of flat heat pipe and equivalent (original) diameter (OD)

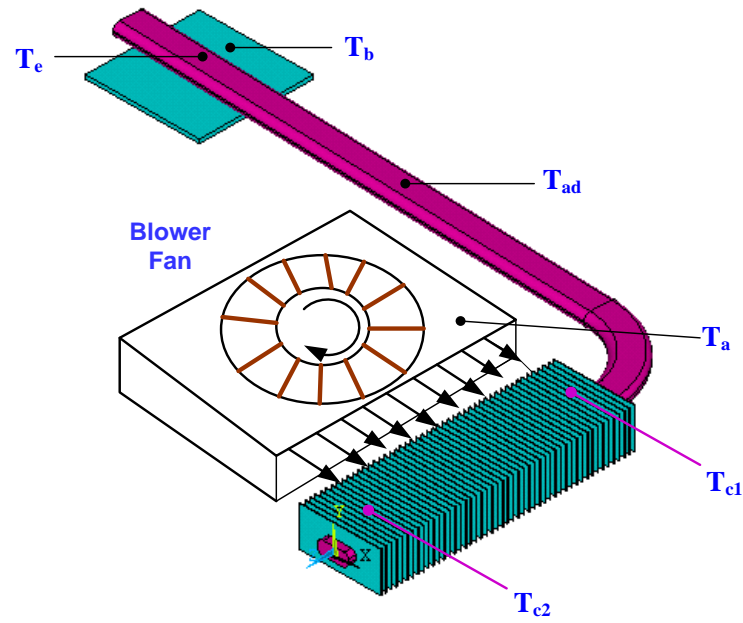

(b) Thermocouples locations

Fig.1. Finned flat heat pipe (a) Heat pipe cross-section (b) Thermocouples locations

Table 1 Specifications of finned L-shape heat pipe

\begin{tabular}{|l|l|}
\hline Characteristic & Dimensions/Material \\
\hline Evaporator length $\mathrm{L}_{\mathrm{e}}$ & $30 \mathrm{~mm}$ \\
\hline Condenser Length $\mathrm{L}_{\mathrm{c}}$ & $72 \mathrm{~mm}$ \\
\hline Adiabatic length $\mathrm{L}_{\mathrm{ad}}$ & $110 \mathrm{~mm}$ \\
\hline Flat heat pipe & $\begin{array}{l}7.6 \mathrm{~mm} \times 3.4 \mathrm{~mm} \\
\text { (width } \times \text { thickness) }\end{array}$ \\
\hline Original diameter $(\mathrm{OD})$ & $6 \mathrm{~mm}$ \\
\hline Heat pipe Container thickness & $0.5 \mathrm{~mm}$ \\
\hline Wick thickness & $0.5 \mathrm{~mm}$ \\
\hline Working fluid & Water \\
\hline Wick structure & Sintered copper powder \\
\hline Material of pipe & Copper \\
\hline
\end{tabular}

The resulting governing equations are listed as follows:

Vapor region

Continuity: $\frac{\partial u_{v}}{\partial x}+\frac{\partial v_{v}}{\partial y}=0$

where $u$ and $v$ are components of velocity in $x$ and $y$ directions, respectively.

\section{Momentum:}

$\rho_{v}\left(u_{v} \frac{\partial u_{v}}{\partial x}+v_{v} \frac{\partial u_{v}}{\partial y}\right)=-\frac{\partial p}{\partial x}+\mu_{v}\left(\frac{\partial^{2} u_{v}}{\partial x^{2}}+\frac{\partial^{2} u_{v}}{\partial y^{2}}\right)$
$\rho_{v}\left(u_{v} \frac{\partial v_{v}}{\partial x}+v_{v} \frac{\partial v_{v}}{\partial y}\right)=-\frac{\partial p}{\partial y}+\rho g+\mu_{v}\left(\frac{\partial^{2} v_{v}}{\partial x^{2}}+\frac{\partial^{2} v_{v}}{\partial y^{2}}\right)$

Energy:

$\rho_{v} c_{p}\left(u_{v} \frac{\partial T}{\partial x}+v_{v} \frac{\partial_{T}}{\partial y}\right)=k_{v}\left(\frac{\partial^{2} T}{\partial x^{2}}+\frac{\partial^{2} T}{\partial y^{2}}\right)$

where, $g$ is the acceleration of gravity, $\rho_{\mathrm{v}}$ vapor density, $\mu_{\mathrm{v}}$ is the effective viscosity of vapor for laminar case is merely the dynamic viscosity, $\mathrm{C}_{\mathrm{p}}$ specific heat and $k_{\mathrm{v}}$ is thermal conductivity of vapor.

\section{Liquid wick region:}

Continuity: $\frac{\partial_{u_{l}}}{\partial_{x}}+\frac{\partial_{v_{l}}}{\partial_{y}}=0$

where, $u$ and $v$ are components of velocity in $\mathrm{x}$ and $\mathrm{y}$ directions, respectively

Momentum:

$\rho_{l}\left(u_{l} \frac{\partial_{u_{l}}}{\partial_{x}}+v_{l} \frac{\partial_{u_{l}}}{\partial_{y}}\right)=-\frac{\partial_{P_{l}}}{\partial_{x}}+\mu_{l}\left(\frac{\partial_{u_{l}}^{2}}{\partial_{x^{2}}}+\frac{\partial_{u_{l}}^{2}}{\partial_{y^{2}}}\right)+R_{x}$

$\rho_{l}\left(u_{l} \frac{\partial_{v_{l}}}{\partial_{x}}+v_{l} \frac{\partial_{v_{l}}}{\partial_{y}}\right)=-\frac{\partial_{P_{l}}}{\partial_{y}}+\rho_{l} g+\mu_{l}\left(\frac{\partial_{v_{l}}^{2}}{\partial_{x^{2}}}+\frac{\partial_{v_{l}}^{2}}{\partial_{y^{2}}}\right)+R_{y}$

$R_{x}$ and $R_{y}$ are distributed resistance components in $x$ and $y$ directions, respectively. A distributed resistance is a convenient way to approximate the effect of porous media. Any fluid element with a distributed resistance will have a real constant set number greater than 1 (ANSYS Release 11.0 documentation 2008). The total liquid pressure gradients along $x$ and $y$ directions are given by (ANSYS Release 11.0 documentation 2008):

$\frac{\partial_{P_{l}}}{\partial_{x_{\text {resistance }}}}=\left\{-K \rho u_{l}\left|u_{l}\right|+\frac{f}{D_{h}} \rho u_{l}\left|u_{l}\right|+C \mu u_{l}\right\}$

$\frac{\partial_{P_{l}}}{\partial_{y_{\text {resistance }}}}=\left\{-K \rho v_{l}\left|v_{l}\right|+\frac{f}{D_{h}} \rho v_{l}\left|v_{l}\right|+C \mu v_{l}\right\}$

where, $\mathrm{K}$ is the localized head loss, $\rho$ is the density, $\mu$ is the viscosity, $f$ is the friction coefficient and $\mathrm{C}$ is the FLOTRAN permeability expressed in $\mathrm{m}^{-2}$, which is inverse of the physical permeability (ANSYS Release 11.0 documentation 2008).

Energy:

$\rho_{l} c_{p, l}\left(u_{l} \frac{\partial_{T_{l}}}{\partial_{x}}+v_{l} \frac{\partial_{T_{l}}}{\partial_{y}}\right)=k_{e}\left(\frac{\partial_{T_{l}}^{2}}{\partial_{x^{2}}}+\frac{\partial_{T_{l}}^{2}}{\partial_{y^{2}}}\right)+Q_{v}$

where, g, $\rho, \mu, \mathrm{C}_{\mathrm{p}}, k_{e}$ and $Q_{v}$ are gravitational acceleration, density, dynamic viscosity, specific heat, effective thermal conductivity for liquid-wick structure and volumetric heat flux respectively. Subscripts $v$ and $l$ refers to vapor and liquid regions respectively. $k_{e}$ is the effective thermal conductivity of the liquid-wick structure for sintered powder wick, as expressed by (Peterson 1994):

$k_{e}=\frac{k_{l}\left[\left(2 k_{l}+k_{w}\right)-2(1-\varphi)\left(k_{l}-k_{w}\right)\right]}{\left(2 k_{l}+k_{w}\right)+(1-\varphi)\left(k_{l}-k_{w}\right)}$

For screen mesh wick, $k_{e}$ calculated from (Peterson 1994):

$k_{e}=\frac{k_{l}\left[\left(k_{l}+k_{w}\right)-(1-\varphi)\left(k_{l}-k_{w}\right)\right]}{\left(k_{l}+k_{w}\right)+(1-\varphi)\left(k_{l}-k_{w}\right)}$ 
where, $\varphi$ is porosity, $\mathrm{k}_{\mathrm{l}}$ and $\mathrm{k}_{\mathrm{w}}$ are thermal conductivity of liquid and wick material respectively.

The steady state thermal conductivity equation to predict the wall temperature is:

$k_{S}\left(\frac{\partial_{T_{s}}^{2}}{\partial_{x^{2}}}+\frac{\partial_{T_{s}}^{2}}{\partial_{y^{2}}}\right)=0$

where, $k_{s}$ is solid thermal conductivity and $\mathrm{T}_{\mathrm{s}}$ is solid (wall) temperature.

\section{Boundary conditions:}

Fig. 2 illustrates the detailed boundary conditions of the computational domain.

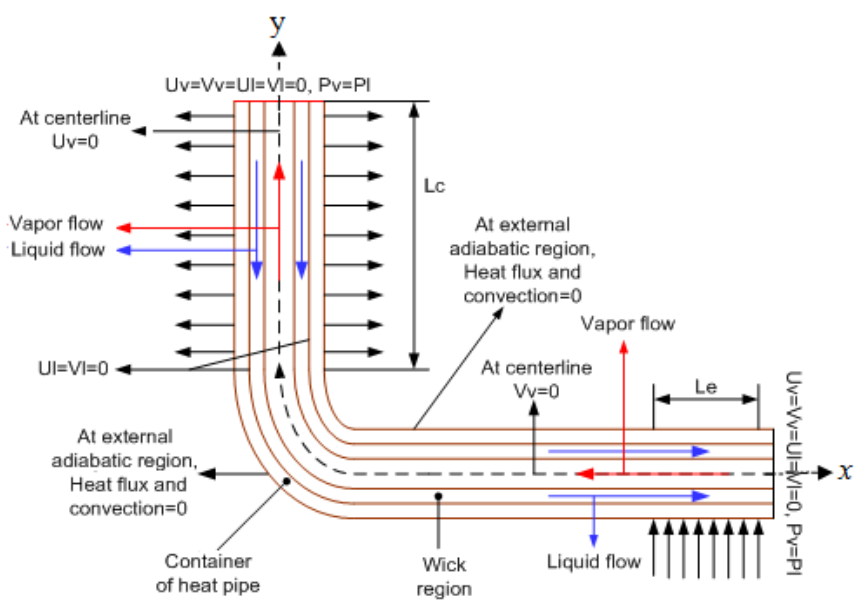

Fig. 2. Illustration of boundary conditions

At both ends of the heat pipe $u_{v}=v_{v}=u_{l}=v_{l}=0$, and $\mathrm{P}_{\mathrm{v}}=\mathrm{P}_{1}$

At the centerline of evaporator section $v_{v}=0, \frac{\partial u_{v}}{\partial y}=0$ and $\frac{\partial T}{\partial y}=0$

At the centerline of condenser section $u_{v}=0, \frac{\partial v_{v}}{\partial x}=0$ and $\frac{\partial T}{\partial x}=0$

For the solid (container) - liquid (wick) interface $u_{l}=v_{l}=0$

At the adiabatic section, $\rho_{\nu} v_{v}=\rho_{l} v_{l}=0$

The continuity of mass fluxes in $y$ direction at the vapor liquid interface yields

$\rho_{v} v_{v}=\rho_{l} v_{l}=-\rho_{v} v_{l}$ where $v_{l}$ is the vapor injection velocity expressed as (Nouri-Borujerdi and Layeghi 2004):

$v_{1}=\frac{Q_{h}}{2 \rho_{v} \pi R_{v} L_{e} h_{f g}}$

Similarly, the continuity of mass fluxes in $x$ direction at the vapor liquid interface yields

$\rho_{v} u_{v}=\rho_{l} u_{l}=\rho_{v} u_{l}$ where $u_{l}$ is the vapor suction velocity as given by (Nouri-Borujerdi and Layeghi 2004):

$u_{1}=\frac{Q_{h}}{2 \rho_{v} \pi R_{v} L_{c} h_{f g}}$

Where, $L_{e}$ and $L_{c}$ are lengths of the evaporator and condenser respectively, and $h_{f g}$ is the latent heat of the working fluid.

The interface temperature $\left(T_{\text {int }}\right)$ is calculated by the ClausiusClapeyron equation, assuming the saturation temperature $\left(T_{0}\right)$ and vapor pressure $\left(P_{0}\right)$ at the liquid-vapor interface (Kaya and Goldak 2007):

$$
T_{\text {int }}=\frac{1}{\frac{1}{T_{0}}-\frac{R}{h_{f g}} \ln \left(\frac{P_{v}}{P_{0}}\right)}
$$

For the solid-liquid interface

At the evaporator part $K_{e} \frac{\partial T_{l}}{\partial y}=k_{S} \frac{\partial T_{s}}{\partial y}$

At the condenser part $K_{e} \frac{\partial T_{l}}{\partial x}=k_{S} \frac{\partial T_{S}}{\partial x}$

At the external heat pipe wall $\left\{\begin{array}{c}\text { Evaporator } k_{S} \frac{\partial T}{\partial y}=q_{e} \\ \text { Adiabatic } \frac{\partial T}{\partial y}=0 \text { and } \frac{\partial T}{\partial x}=0 \\ \text { Condenser }-k_{S} \frac{\partial T}{\partial x}=h\left(T_{S}-T_{a}\right)\end{array}\right\}$

where, $h$ is convection heat transfer coefficient, and $T_{s}$ and $T_{a}$ are wall surface and ambient temperatures respectively.

\section{MESHING AND NUMERICAL SOLUTION}

The modeling approach was adapted to the works of (Zhu and Vafai 1999), (Kaya and Goldak 2007) and (Nouri-Borujerdi and Layeghi 2004), taking into account the amendments to suit the L-shape heat pipe and the simulations were done by using ANSYS-FLOTRAN. The heat from the base was transferred to the heat pipe and then to the fins and from fins to the surrounding air. In the present two-dimensional numerical simulation of the flat heat pipe an obstacle was that the top view section was broad $(7.6 \mathrm{~mm})$ while the side view section was thin $(3.4 \mathrm{~mm})$ as shown in Fig. 1(a), and this prompted to calculate the equivalent diameter of the heat pipe. Accordingly, by assuming the flat heat pipe as cylindrical heat pipe of equivalent perimeter, the equivalent diameter of the flat heat pipe was obtained as $6 \mathrm{~mm}$.

The computational domain is divided into two estranged regions: 1) vapor region, and 2) liquid-wick structure and heat pipe wall. The simulation is carried out by using the element FLUID141. The vapor region is meshed with 4900 fine triangular elements, whereas the liquid-wick and solid regions are given relatively very finer meshing, forming 52456 triangular elements. Preconditioned Conjugate Gradient (PCG) was used as iterative solvers. The convergence criterion was taken as $1 \mathrm{e}-007$ were the convergence criterion is a value below which the convergence monitors for each active degree of freedom must drop to cause the time step to terminate (ANSYS Release 11.0 documentation 2008). For solving the set of vapor matrix equations, the Conjugate Residual Method was used; however when solving equations of solid and liquid simultaneously, the non-symmetric matrix equations appeared, and to overcome this phenomenon the Preconditioned Biconjugate Gradient Stabilized Method (BiCGSTAB) was selected.

\section{RESULTS AND DISCUSSION}

\subsection{Natural Convection}

In the natural convection mode, the simulation was performed with heat input of $20 \mathrm{~W}$. At natural convection, the physical properties of the working fluid were taken at $120^{\circ} \mathrm{C}$ as summarized in Table 2 .

The wick structure consisted of sintered copper powder wick which has fine pore size causing low permeability $\left(1.17 \times 10^{-1} 1 \mathrm{~m} 2\right)$ (Mwaba et al. 2006). The effective thermal conductivity of liquid-wick structure is $3.69 \mathrm{~W} / \mathrm{mK}$, which was calculated from Eq. (11).

The wall temperature results were compared with experimental data to verify the accuracy of the simulation results at the same operation conditions. 
Table 2 Physical properties of water and vapor at $120^{\circ} \mathrm{C}$ (Faghri 1995)

\begin{tabular}{|l|l|l|}
\hline & Water & Vapor \\
\hline Density $\mathrm{kg} / \mathrm{m}^{3}$ & 945 & 1.12 \\
\hline Viscosity $\mathrm{kg} / \mathrm{m} . \mathrm{s}$ & $2.6 \times 10^{-4}$ & $1.34 \times 10^{-5}$ \\
\hline Thermal conductivity W/mK & 0.682 & 0.0234 \\
\hline Latent heat $\mathrm{J} / \mathrm{kg}$ & $2.2 \times 10^{6}$ & - \\
\hline Surface tension N/m & 0.055 & - \\
\hline Pressure $\mathrm{N} / \mathrm{m}^{2}$ & - & $2.02 \times 10^{5}$ \\
\hline
\end{tabular}

As shown in Fig. 3, the highest temperature reaches to $126.74{ }^{\circ} \mathrm{C}$, located in the evaporator and then falls relatively in the adiabatic section to $120{ }^{\circ} \mathrm{C}$ and the temperature stay uniform in this region and then the temperature drops again to $114.94{ }^{\circ} \mathrm{C}$ in the condenser section. It is worth noting that the simulation temperatures including evaporator temperature $\left(\mathrm{T}_{\mathrm{e}}\right)$, adiabatic section temperature $\left(\mathrm{T}_{\mathrm{ad}}\right)$, condenser temperatures $\left(\mathrm{T}_{\mathrm{c} 1}\right)$ and $\left(\mathrm{T}_{\mathrm{c} 1}\right)$ are $125.19{ }^{\circ} \mathrm{C}, 120.0^{\circ} \mathrm{C}, 119.45^{\circ} \mathrm{C}$, and $114.87{ }^{\circ} \mathrm{C}$ respectively which are close to the experimental results except in the adiabatic section temperature $\left(\mathrm{T}_{\mathrm{ad}}\right)$ which is less satisfactory due to the assumption of no heat loss in the adiabatic section. Moreover, as the experiment is isolated by glass tunnel, the adiabatic temperature affected by the removal heat. The good agreement indicates the validity of the present simulation methodology.

\section{-2D numerical results $\Delta$ experimental results}

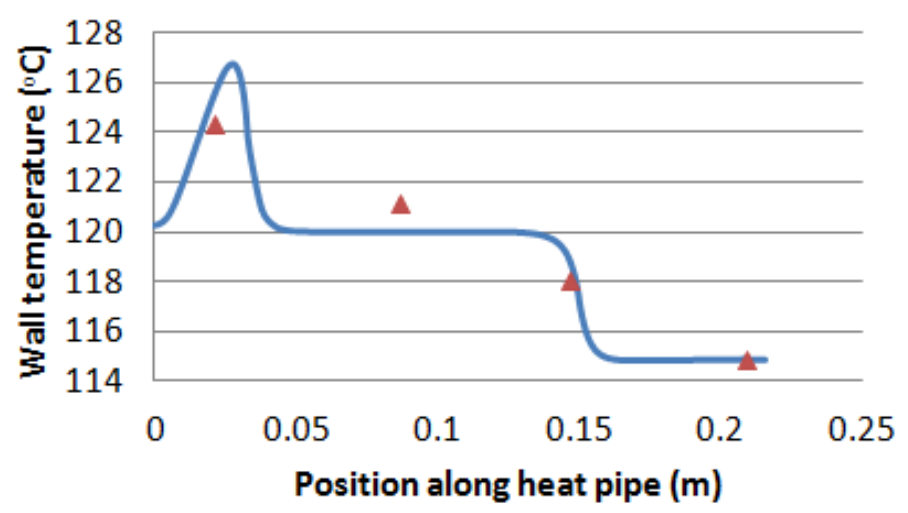

Fig. 3. Wall temperature distribution along the heat pipe at $Q=20 \mathrm{~W}$ in natural convection and comparison with the experimental results.

\section{Methanol as working fluid}

A comparative study was made by replacing water with methanol as working fluid. In the natural convection mode, the simulation was performed with heat input of $20 \mathrm{~W}$. At $\mathrm{Q}=20 \mathrm{~W}$ and natural convection, the physical properties of the working fluid were taken at $120{ }^{\circ} \mathrm{C}$ as summarized in Table 3.

Table 3 Physical properties of liquid and vapor of methanol at $120^{\circ} \mathrm{C}$

\begin{tabular}{|l|l|l|}
\hline & Liquid & Vapor \\
\hline Density $\mathrm{kg} / \mathrm{m}^{3}$ & 696 & 7.7 \\
\hline Viscosity $\mathrm{kg} / \mathrm{m} . \mathrm{s}$ & $2.0 \times 10^{-4}$ & $1.28 \times 10^{-5}$ \\
\hline Thermal conductivity W/mK & 0.196 & 0.0022 \\
\hline Latent heat $\mathrm{J} / \mathrm{kg}$ & $0.95 \times 10^{6}$ & - \\
\hline Surface tension N/m & 0.0135 & - \\
\hline Pressure $\mathrm{N} / \mathrm{m}^{2}$ & - & $6.41 \times 10^{5}$ \\
\hline
\end{tabular}

The use of screen mesh wick with porosity 0.62 and permeability1.93 $\times 10-10$ (Mwaba et al. 2006) and water as working fluid resulted in value of effective thermal conductivity of water-wick structure $1.42 \mathrm{~W} / \mathrm{mK}$ according to Eq. (12). As noted in Table 3, the thermal conductivity of methanol is small $(0.196 \mathrm{~W} / \mathrm{mK})$ compared with water $(0.682 \mathrm{~W} / \mathrm{mK})$ at the same operating temperature. This leads to low effective thermal conductivity of Liquid-wick region 0.445 $\mathrm{W} / \mathrm{mK}$. In order to know the influence of the wick thickness on the thermal performance of L-shape heat pipe in the present simulation, the wick thicknesses were taken as $0.5 \mathrm{~mm}$ to $0.75 \mathrm{~mm}$ for using both water and methanol as working fluids.

Fig. 4 shows the wall temperature distribution of the heat pipe in natural convection with reference to change in working fluid and thicknesses of screen mesh wick $\left(\mathrm{K}=1.93 \times 10^{-10} \mathrm{~m}^{2}\right)$ at $\mathrm{Q}=20 \mathrm{~W}$. It is observed that use of water as working fluid leads to small temperature difference between evaporator and condenser compared to that with methanol as working fluid. This is attributed to the fact that the thermal conductivity of water is higher than that of methanol, which leads to the increase of effective thermal conductivity of water-wick region. The effect of wick thickness is also observed in Fig. 4; the temperature difference of the heat pipe with wick thickness $0.5 \mathrm{~mm}$ is less than that with wick thickness $0.75 \mathrm{~mm}$. Water with $0.5 \mathrm{~mm}$ screen mesh wick recorded the smallest temperature difference $\left(24.56^{\circ} \mathrm{C}\right)$ while methanol with $0.75 \mathrm{~mm}$ screen mesh wick recorded the largest $\left(54^{\circ} \mathrm{C}\right)$. It is also observed that the temperature distribution at the adiabatic region is uniform and constant at about $120^{\circ} \mathrm{C}$ for all the cases.
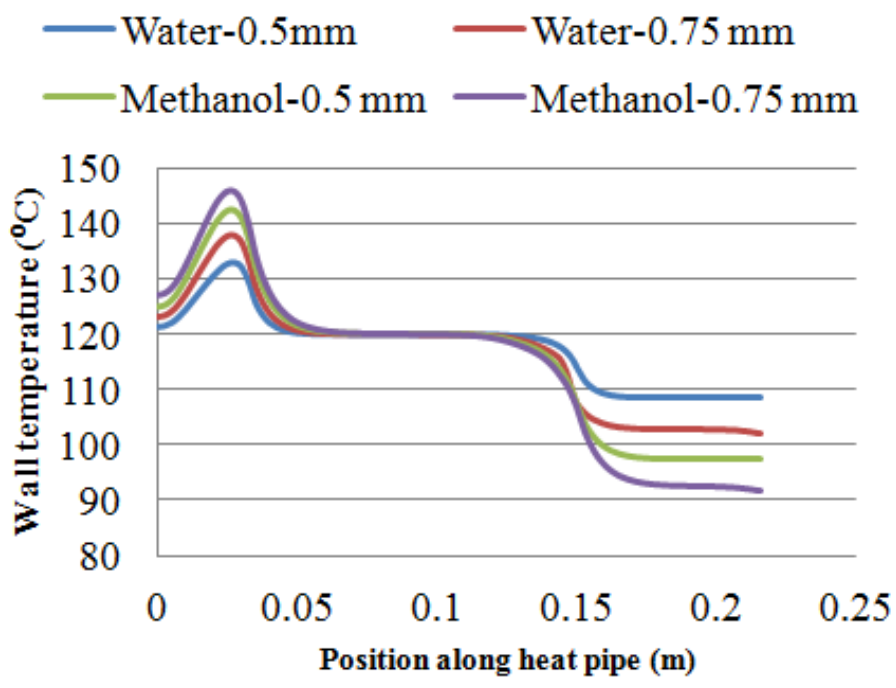

Fig. 4. Wall temperature distribution of heat pipe in natural convection with reference to variation of working fluid and thicknesses of screen mesh wick $\left(\mathrm{K}=1.93 \times 10^{-10} \mathrm{~m}^{2}\right)$ at $\mathrm{Q}=20 \mathrm{~W}$.

The comparison of heat pipes with screen mesh wick and different working fluids and wick thicknesses, is shown in Fig. 5. With increasing wick thickness, the flow area increases and it causes decrease in pressure drop in the liquid-wick region. It is observed that the maximum liquid pressure drop $(692.43 \mathrm{~Pa})$ is obtained for methanol with $0.5 \mathrm{~mm}$ wick thickness while the minimum pressure drop (338.94 $\mathrm{Pa}$ ) is obtained for water with $0.75 \mathrm{~mm}$ wick thickness. Although the liquid pressure drop of methanol is large owing to its higher viscosity, the pressure drop of water with wick thickness of $0.5 \mathrm{~mm}(501.81 \mathrm{~Pa})$ is greater than that of methanol with wick thickness of $0.75 \mathrm{~mm} \mathrm{(468.37}$ $\mathrm{Pa}$ ). This indicates that the effect of thickness on the pressure drop is more significant than the effect of the type of liquids used.

\subsection{Forced Convection}

In this mode, the applied heat is $35 \mathrm{~W}$ with coolant airflow rate of $6.5 \mathrm{~m} 3 / \mathrm{h}$. As shown in Fig. 6, the highest temperature $\left(52.94{ }^{\circ} \mathrm{C}\right)$ is located at the evaporator section. The adiabatic area between the evaporator and condenser has uniform temperature distribution about $47^{\circ} \mathrm{C}$, and it begins to decline at the condenser region to reach to $43.05^{\circ} \mathrm{C}$ towards the end of the condenser section. 

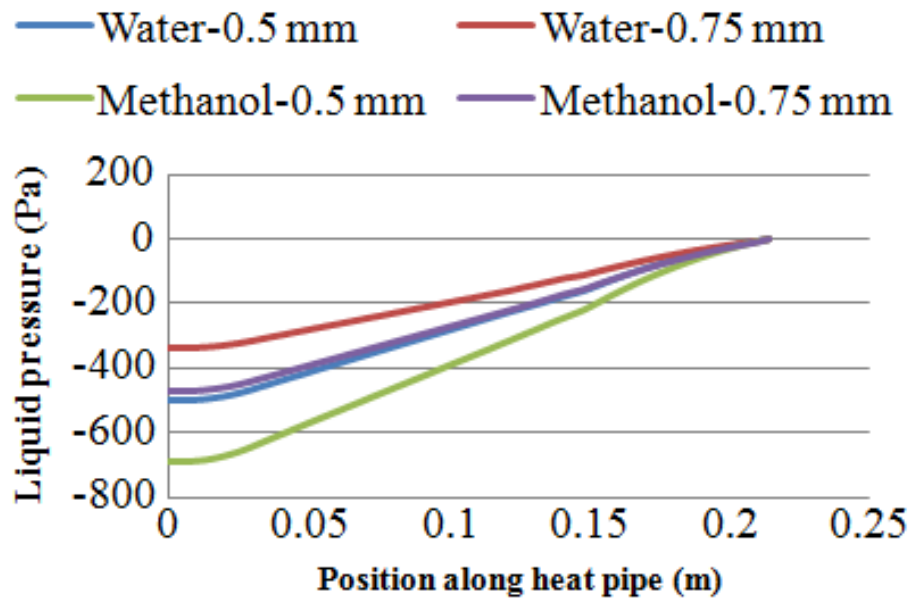

Fig. 5. Liquid pressure distribution along the heat pipe at $\mathrm{Q}=20 \mathrm{~W}$ in natural convection with various wick thicknesses (Screen mesh $\mathrm{K}=1.93 \times 10^{-10} \mathrm{~m}^{2}$ ).

Fig. 6 shows the wall temperature distribution along the heat pipe at coolant airflow of $6.5 \mathrm{~m} 3 / \mathrm{h}$. The predict temperatures Te, Tad, Tc1 and Tc1 are observed to be $51.52{ }^{\circ} \mathrm{C}, 47.00^{\circ} \mathrm{C}, 46.23{ }^{\circ} \mathrm{C}$, and $43.06{ }^{\circ} \mathrm{C}$ respectively; this decline in temperatures is obviously due to the enhanced cooling by forced convection. These values of temperatures are in good agreement with experimental results except evaporator temperature $\left(\mathrm{T}_{\mathrm{e}}\right)$. This is due to $\left(\mathrm{T}_{\mathrm{e}}\right)$ being affected by cooling air flow which decreases it.

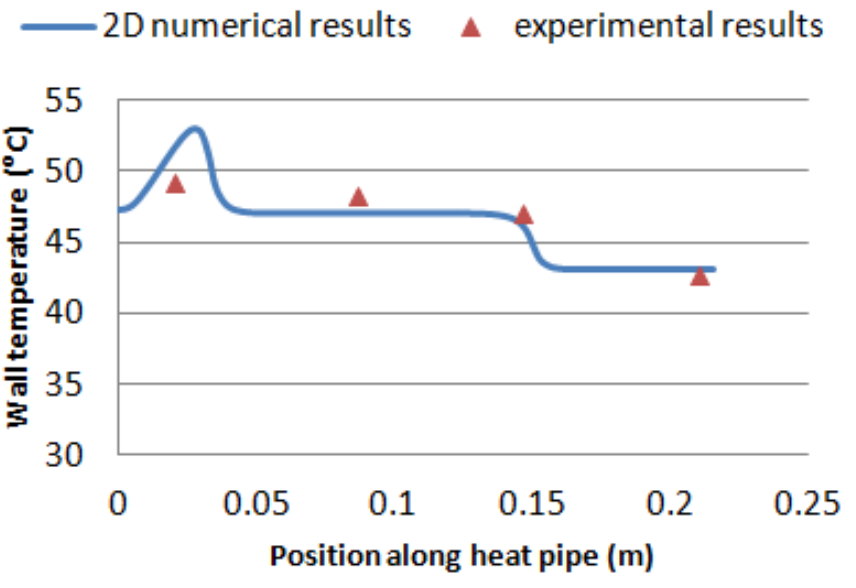

Fig. 6. Predicted temperature distribution along heat pipe at $Q=35 \mathrm{~W}$ with coolant airflow rate of $6.5 \mathrm{~m}^{3} / \mathrm{h}$ and comparison with the experimental results.

In order to show the effect of parameters and compare their influences on the performance of heat pipe under forced convection, the parameters are collected in Fig. 7. It is observed that the use of sintered copper powder wick leads to small temperature difference between evaporator and condenser compared to screen mesh wick as the sintered copper wick has low permeability $1.17 \times 10-11 \mathrm{~m}^{2}$, which causes increase of effective thermal conductivity of wick region. Additionally, the use of water as working fluid leads to small temperature difference compared to that with methanol as working fluid. This is because the thermal conductivity of water is higher than that of methanol, which increases the effective thermal conductivity of water-wick region compared to the methanol-wick region. The effect of wick thickness is also observed; the temperature difference of the heat pipe with wick thickness $0.5 \mathrm{~mm}$ is less than that of heat pipe with wick thickness 0.75 $\mathrm{mm}$. The water with $0.5 \mathrm{~mm}$ sintered copper wick recorded the smallest temperature difference $\left(9.8^{\circ} \mathrm{C}\right)$ while methanol with $0.75 \mathrm{~mm}$ screen mesh wick recorded the largest temperature difference $\left(28.27^{\circ} \mathrm{C}\right)$. It is also observed that there is a rapprochement between the temperature distribution of water with $0.75 \mathrm{~mm}$ screen mesh wick and methanol with 0.5 screen mesh wick. Additionally, it is observed that the temperature distribution at the adiabatic region is uniform and constant about $47{ }^{\circ} \mathrm{C}$ for all cases. Methanol with copper powder wick was excluded because it results in exceedingly high pressure in the liquidwick region.

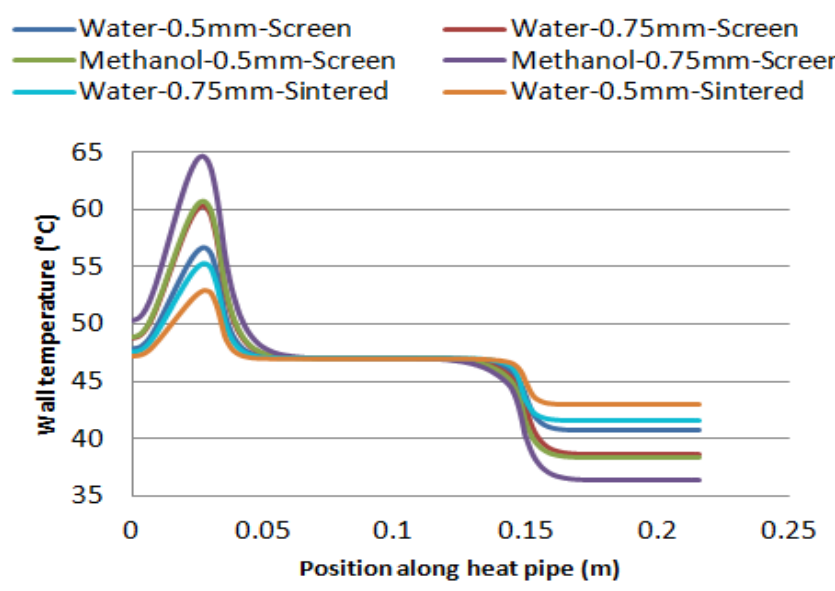

Fig. 7. Wall temperature distribution along the heat pipe at $\mathrm{Q}=35 \mathrm{~W}$ and forced convection $\left(Q^{*}=6.5 \mathrm{~m}^{3} / \mathrm{h}\right)$ with various working fluid and wick types and thicknesses.

In the forced convection, heat input of $35 \mathrm{~W}$ is used, with increasing heat input, the flow rate of liquid increases, so it causes of increasing the pressure drop in liquid region. Fig. 8 shows the liquid pressure distribution along the heat pipe at $\mathrm{Q}=35 \mathrm{~W}$ under forced convection $\left(\mathrm{Q}^{*}=6.5 \mathrm{~m}^{3} / \mathrm{h}\right)$ with various sintered copper wick thicknesses. It is observed that liquid pressure drop is decreased from $6563 \mathrm{~Pa}$ to 4219 $\mathrm{Pa}$ when the wick thickness is increased from $0.5 \mathrm{~mm}$ to $0.75 \mathrm{~mm}$, as increasing the thickness of the wick leads to increase in the liquid flow area through the wick, which causes reduction in liquid pressure drop liquid-wick region.

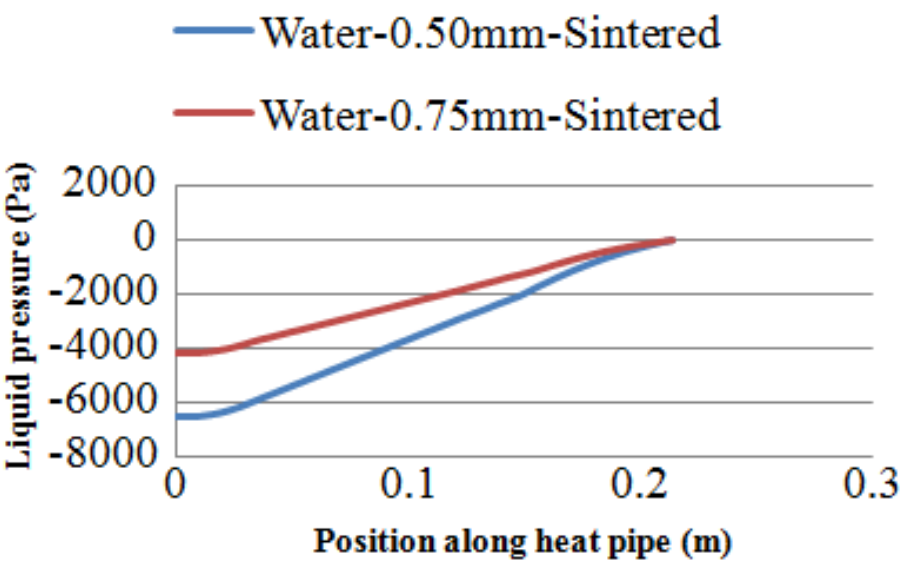

Fig. 8. Predict liquid (Water) pressure distribution at $Q=35 \mathrm{~W}$ in forced convection $\left(Q^{*}=6.5 \mathrm{~m}^{3} / \mathrm{h}\right)$ of sintered copper powder wick with various thicknesses.

Fig. 9 clearly shows the comparison of heat pipes with screen mesh wicks of difference working fluids and wick thicknesses. It is observed that the maximum liquid pressure drop $(1789 \mathrm{~Pa})$ is obtained when methanol with $0.5 \mathrm{~mm}$ wick thickness is used, while the minimum pressure drop $(633 \mathrm{~Pa})$ is obtained when water with $0.75 \mathrm{~mm}$ wick thickness is used. Although the liquid pressure drop of methanol is 
large due to its higher viscosity, the pressure drop of methanol with wick thickness of $0.75 \mathrm{~mm}(1083 \mathrm{~Pa})$ is less than the pressure of water with wick thickness of $0.5 \mathrm{~mm}(1129 \mathrm{~Pa})$. This is because, the increased thickness of the wick leads to increase in the liquid flow area through the wick, which causes reduction in liquid pressure drop at the liquidwick region.
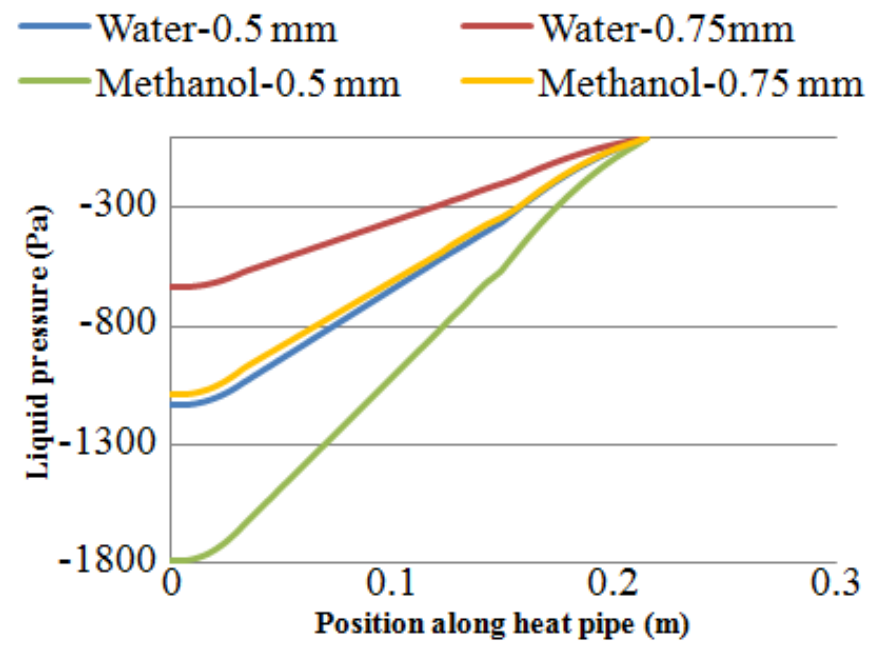

Fig. 9 Liquid pressure distribution along the heat pipe at $Q=35 \mathrm{~W}$ at $\mathrm{Q}^{*}=6.5 \mathrm{~m}^{3} / \mathrm{h}$ with various working fluid and wick thickness at Screen mesh

\section{CONCLUSION}

A two-dimensional FEM simulation of working fluid behavior inside Lshape heat pipe was performed by using ANSYS-FLOTRAN software to study the effect of thickness and permeability of wick structure using water and methanol as different working fluids on L-shape heat pipe performance.

The study concluded with the following key points:

-The increase in thickness of the wick caused a decrease in liquid pressure drop in the liquid-wick region while the use of methanol as working fluid increased the liquid pressure.

-The use of sintered copper powder wick resulted in small temperature difference between the evaporator and condenser compared to screen mesh wick.

-Although good performance of heat pipe was achieved by employing water with $0.5 \mathrm{~mm}$ thickness of sintered copper powder, the unfavorable high pressure resulted in low heat transport capability at the liquid-wick region.

\section{REFERENCES}

ANSYS Release 11.0 documentation, Cartographer, 2008. http://www.ansys.stuba.sk/html/elem 55/chapter4/ES4-141.htm

Carbajal, G., Sobhan, C. B., Peterson, G. P., Queheillalt, D. T., and Wadley, H. N. G., 2007, "A quasi-3D analysis of the thermal performance of a flat heat pipe," International Journal of Heat and Mass Transfer, 50(21-22), 4286-4296.

http://dx.doi.org/10.1016/j.ijheatmasstransfer.2007.01.057

Do, K. H., and Jang, S. P., 2010, "Effect of nanofluids on the thermal performance of a flat micro heat pipe with a rectangular grooved wick," International Journal of Heat and Mass Transfer, 53(9-10), 2183-2192. http://dx.doi.org/10.1016/j.ijheatmasstransfer.
Do, K. H., Kim, S. J., and Garimella, S. V., 2008, "A mathematical model for analyzing the thermal characteristics of a flat micro heat pipe with a grooved wick," International Journal of Heat and Mass Transfer, 51(19-20), 4637-4650.

http://dx.doi.org/10.1016/j.ijheatmasstransfer.2008.02.039

Faghri, A., 1994, "Recent advances in the numerical analysis of heat pipes," Computational Mechanics, 14(5), 480-491.

DOI: $10.1007 / \mathrm{bf} 00377600$

Faghri, A.,1995, Heat Pipe Science and Technology, Taylor \& Francis Group.

Faghri, A., and Khrustalev, D., 1997, "Advances in Modeling of Enhanced Flat Miniature Heat Pipes with Capillary Grooves, "Journal of Enhanced Heat Transfer, 4(2), 99-109.

http://dl.begellhouse.com/journals/4c8f5faa331b09ea,3794e5900f95358 $\underline{\mathrm{e}, 4 \mathrm{~d} 4 \mathrm{aad} 4 \mathrm{~d} 2 \mathrm{dd} 382 \mathrm{c} 1 . \mathrm{html}}$

Groll, M., Schneider, M., Sartre, V., Chaker Zaghdoudi, M., and Lallemand, M., 1998, "Thermal control of electronic equipment by heat pipes," Revue Générale de Thermique, 37(5), 323-352.

http://dx.doi.org/10.1016/S0035-3159(98)80089-5

Jacolot, R., Romestant, C., Ayel, V., Bertin, Y., and Hugon, J., 2008, "Visualization and Experimental Analysis of Fluid Behavior in Grooved Heat Pipes," Experimental Heat Transfer, 21(3), 188 - 205. DOI: $10.1080 / 08916150802072842$

Kaya, T., and Goldak, J., 2007, "Three-dimensional numerical analysis of heat and mass transfer in heat pipes," Heat and Mass Transfer, 43(8), 775-785.

DOI: $10.1007 / \mathrm{s} 00231-006-0166-\mathrm{y}$

Khrustalev, D., and Faghri, A., 1995a, "Heat Transfer During Evaporation on Capillary-Grooved Structures of Heat Pipes," Journal of Heat Transfer, 117(3), 740-747.

http://link.aip.org/link/?JHR/117/740/1

Khrustalev, D., and Faghri, A., 1995b, "Thermal Characteristics of Conventional and Flat Miniature Axially Grooved Heat Pipes," Journal of Heat Transfer, 117(4), 1048-1054.

http://dx.doi.org/10.1115/1.2836280

Khrustalev, D., and Faghri, A, 1999, "Coupled Liquid and Vapor Flow in Miniature Passages With Micro Grooves," Journal of Heat Transfer, 121(3), 729-733.

http://dx.doi.org/10.1115/1.2826042

Mahjoub, S., and Mahtabroshan, A., 2008, "Numerical Simulation of a Conventional Heat Pipe," Proceedings Of World Academy Of Science, Engineering And Technology, 29, 117-122.

http://www.waset.org/journals/waset/v15/v15-22.pdf

Maziuk, V., Kulakov, A., Rabetsky, M., Vasiliev, L., and Vukovic, M., 2001, "Miniature heat-pipe thermal performance prediction tool software development," Applied Thermal Engineering, 21(5), 559-571. doi: 10.1016/S1359-4311(00)00066-1

Mistry, P. R., Thakkar, F. M., De, S., and DasGupta, S., 2010, "Experimental Validation of a Two-Dimensional Model of the Transient and Steady-State Characteristics of a Wicked Heat Pipe," Experimental Heat Transfer, 23(4), 333 - 348.

DOI: $10.1080 / 08916150903564804$ 
Mwaba, M. G., Huang, X., and Gu, J., 2006, "Influence of wick characteristics on heat pipe performance, "International Journal of Energy Research, 30(7), 489-499.

DOI: $10.1002 /$ er. 1164

Nouri-Borujerdi, A., and Layeghi, M., 2004, "A Numerical Analysis of Vapor Flow in Concentric Annular Heat Pipes," Journal of Fluids Engineering, 126(3), 442-448.

http://dx.doi.org/10.1115/1.1760549

Peterson, G. P., 1994, An Introduction to heat pipes: Modeling, Testing, and Applications, New York: John Wiley \& Sons, INC.

Shao, W., and Zhang, Y., 2011, "Effects of Capillary and Gravitational Forces on Performance of An Oscillating Heat Pipe," Frontiers in Heat Pipes (FHP), 2, 023003.

http://dx.doi.org/10.5098/fhp.v2.2.3003
Vasiliev, L. L., 2005, "Heat pipes in modern heat exchangers," Applied Thermal Engineering, 25(1), 1-19.

DOI: 10.1016/j.applthermaleng.2003.12.004

Wang, Y., and Vafai, K., 2000, "An experimental investigation of the thermal performance of an asymmetrical flat plate heat pipe," International Journal of Heat and Mass Transfer, 43(15), 2657-2668. DOI: 10.1016/S0017-9310(99)00300-2

Zhang, Y., and Faghri, A., 2001, "Numerical Simulation Of Condensation On A Capillary Grooved Structure," Numerical Heat Transfer, Part A: Applications, 39(3), 227-243.

DOI: $10.1080 / 104077801300006562$

Zhu, N., and Vafai, K., 1999, "Analysis of cylindrical heat pipes incorporating the effects of liquid-vapor coupling and non-Darcian transport--a closed form solution" International Journal of Heat and Mass Transfer, 42(18), 3405-3418.

DOI: $10.1016 / \mathrm{S} 0017-9310(99) 00017-4$ 